\title{
Design of an Agent-Based Visual Programming Tool for Elementary Ecosystem Science Learning
}

\author{
Shari Metcalf \\ Harvard University \\ Cambridge, MA USA \\ shari_metcalf@gse.harvard.edu \\ Karen Brennan \\ Harvard University \\ Cambridge, MA USA \\ karen_brennan@gse.harvard.edu
}

\author{
Amanda Dickes \\ Harvard University \\ Cambridge, MA USA \\ amanda_dickes@gse.harvard.edu \\ Chris Dede \\ Harvard University \\ Cambridge, MA USA \\ chris_dede@gse.harvard.edu
}

\begin{abstract}
Computational thinking and scientific modeling are essential STEM education practices, and visual block-based programming interfaces offer new opportunities to make coding accessible in elementary school science. The EcoMOD research project blends computational modeling and ecosystem science learning through a $3 \mathrm{D}$ virtual forest ecosystem combined with a $2 \mathrm{D}$ visual blockbased programming tool, for $3^{\text {rd }}$ and $4^{\text {th }}$ grade students (ages 810). During a 14-day curriculum, students explore an immersive virtual forest ecosystem, and program agent-based computational models of a beaver building a dam. As students run their program and watch their beaver agent go through the steps of building a dam, they observe the emergent outcomes as their programmed model impacts other elements of the ecosystem. The final curriculum was implemented with 7 teachers and approximately 150 students.
\end{abstract}

A scaffolded coding interface provides domain-specific programming primitives, such as "move toward tree," "bite tree," and "pick up log." Conditional expressions include "if", "if/otherwise," and "repeat until," and can be nested. The interface provides a virtual 2D sandbox to test and edit programs, visual feedback during code execution, and debugging supports. Using design-based research methods, different sets of primitives and functionality were tested with students. Analysis of computational models constructed by students uses logfile data of programming activities over multiple class periods, as well as screen capture video of focus students. The poster will include design insights for the agent-based modeling language, including choices of primitives, conditionals, and scaffolding.

\section{CCS CONCEPTS}

- Social and professional topics Children - Social and professional topics Computational thinking - Social and professional topics Computer science education - Applied computing Interactive learning environments - Software and its engineering Domain specific languages - Software and its engineering $\sim$ Visual languages

\section{KEYWORDS}

Introductory Visual Programming Environments; Elementary Computer Science Education; Ecosystem Science Education; Block-based Programming; Agent-Based Programming

\section{ACM Reference format:}

Shari Metcalf, Amanda Dickes, Karen Brennan, Chris Dede. 2019. Design of an Agent-Based Visual Programming Tool for Elementary Ecosystem Science Learning. In Proceedings of ACM International Computing Education Research conference (ICER'19), August 12-14, 2019, Toronto, ON, Canada. ACM, New York, NY, USA.

https://doi.org/10.1145/3291279.3341210
Permission to make digital or hard copies of all or part of this work for personal or classroom use is granted without fee provided that copies are not made or distributed for profit or commercial advantage and that copies bear this notice and the full citation on the first page. Copyrights for third-party components of this work must be honored. For all other uses, contact the Owner/Author.

ICER'19, August 12-14 2019, Toronto, ON, Canada.

๑) 2019 Copyright is held by the owner/author(s).

ACM ISBN 978-1-4503-6185-9/19/08.

https://doi.org/10.1145/3291279.3341210 